\title{
Low Temperature Growth of Single-Walled Carbon Nanotubes from Pt Catalysts under Low Ethanol Pressure by Alcohol Gas Source Method
}

\author{
Hiroki Kondo, Naoya Fukuoka, and Takahiro Maruyama \\ Department of Materials Science and Engineering, Meijo University, Nagoya 468-8502, Japan \\ Correspondence should be addressed to Takahiro Maruyama, takamaru@meijo-u.ac.jp \\ Received 14 June 2012; Accepted 15 September 2012 \\ Academic Editor: Magnus Willander \\ Copyright (c) 2012 Hiroki Kondo et al. This is an open access article distributed under the Creative Commons Attribution License, \\ which permits unrestricted use, distribution, and reproduction in any medium, provided the original work is properly cited.

\begin{abstract}
Growth of single-walled carbon nanotubes (SWNTs) was carried out on $\mathrm{SiO}_{2} / \mathrm{Si}$ substrates with Pt catalysts at 400,450 , and $700^{\circ} \mathrm{C}$ under various ethanol pressures using an alcohol gas source method in a high vacuum, and the grown SWNTs were characterized by scanning electron microscopy (SEM) and Raman spectroscopy. Irrespective of the growth temperature, both G band and RBM peaks were observed in the Raman spectra under the optimal ethanol pressure $\left(\sim 1 \times 10^{-3} \mathrm{~Pa}\right)$, indicating that SWNTs grew below $450^{\circ} \mathrm{C}$ from Pt. At $400^{\circ} \mathrm{C}$, both average diameter and diameter distribution were drastically reduced, and those were fairly smaller and narrower, compared to those for SWNTs grown with Co.
\end{abstract}

\section{Introduction}

Single-walled carbon nanotubes (SWNTs) have attracted great interest for nanometer-scale devices, such as field effect transistor (FET) $[1,2]$ and LSI interconnects [3, 4]. Among a lot of methods for SWNTs growth, catalytic chemical vapor deposition (CVD) has several advantages such as high yield production, low growth temperature, and good controllability of SWNT position and diameter. As a result, CVD is widely used for the SWNT growth at present [5]. To realize SWNT-based devices compatible with LSI manufacturing processes, SWNT growth by CVD under low pressure is significant since the SWNT growth under a high vacuum prevents surface contamination during the fabrication process. In addition, SWNT growth in a high vacuum is useful for in situ observations during the growth, such as scanning electron microscopy (SEM) and transmission electron microscopy (TEM).

Thus far, SWNT growth using CVD under low pressure has been performed by several groups. For the purpose of in situ observations, Homma et al. carried out carbon nanotube (CNT) growth by low-pressure alcohol CVD at $1-$ $20 \mathrm{~Pa}[6,7]$. Shiokawa et al. succeeded in growing SWNTs by a cold-wall CVD using ethanol at $0.05 \mathrm{~Pa}$ in an ultrahigh vacuum (UHV) chamber [8]. Our group also achieved SWNT growth at an ambient ethanol pressure of $1 \times 10^{-4} \mathrm{~Pa}$ with a Co catalyst, adopting a gas source method in a UHV chamber, a type of cold-wall CVD. However, the SWNT yield decreased considerably, because the growth temperature had to be reduced to $400^{\circ} \mathrm{C}$ to obtain SWNTs under low ethanol pressure [9-11].

Recently, we grew SWNTs using Pt catalysts and showed that SWNTs could be grown even at ambient ethanol pressure of $1 \times 10^{-4} \mathrm{~Pa}$, while keeping the yield compatible with Co catalysts at $1 \times 10^{-1} \mathrm{~Pa}[12,13]$. However, it is desirable to reduce the growth temperature to $400^{\circ} \mathrm{C}$ for application to fabrication of SWNT devices compatible with present CMOS, since low dielectric constant intermetal dielectrics in the device structures are mechanically deteriorated above $400^{\circ} \mathrm{C}$.

In this study, we carried out SWNT growth on $\mathrm{SiO}_{2} / \mathrm{Si}$ substrates using Pt catalyst under various temperatures. By optimizing the ethanol pressure, SWNTs could be grown even at $400^{\circ} \mathrm{C}$. We also investigated the structural properties of grown SWNTs by SEM and Raman measurements. 


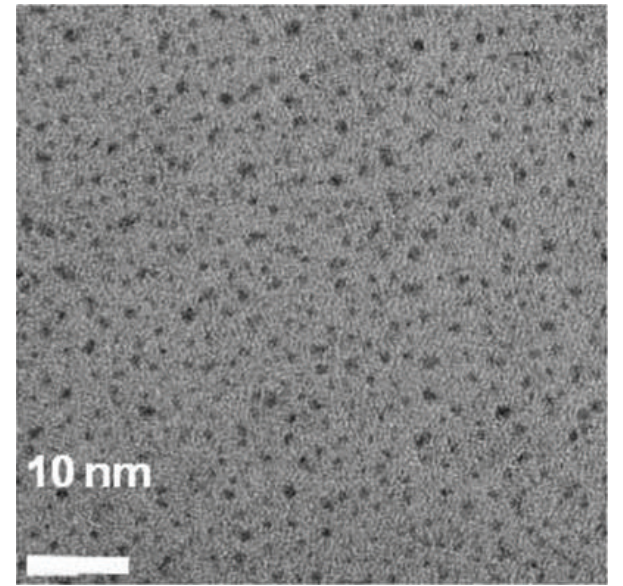

Figure 1: TEM image of Pt catalysts deposited on a TEM grid with $\mathrm{SiO}_{2}$ membrance. The nominal thickness of Pt was $0.2 \mathrm{~nm}$.

\section{Experimental Procedure}

$\mathrm{SiO}_{2} / \mathrm{Si}$ substrates were used for the SWNT growth. After deposition of a Pt catalyst by a pulsed arc plasma gun in a UHV chamber, the substrate was introduced to a UHV chamber equipped with an ethanol introduction system and a substrate holder with a heater. The chamber was evacuated to a base pressure less than $1 \times 10^{-6} \mathrm{~Pa}$ with a turbomolecular pump. This system was a cold-wall type CVD, where the substrate was locally heated by the heater. Then, we increased the substrate temperature to the growth temperature under $\mathrm{H}_{2}$ gas flow at a pressure of $1 \times 10^{-3} \mathrm{~Pa}$ to prevent oxidation of the catalyst. The substrate temperature was monitored by a pyrometer and the Pt thickness was monitored with a quartz crystal oscillator. In this experiment, the nominal thickness of Pt was set to $0.2 \mathrm{~nm}$, which was the optimal thickness to obtain the highest SWNT yield. A TEM image for the $\mathrm{SiO}_{2} / \mathrm{Si}$ after the deposition of $\mathrm{Pt}(0.2 \mathrm{~nm})$ is shown in Figure 1. Pt particles whose average diameter was about $1 \mathrm{~nm}$ were observed, indicating that Pt catalyst formed particle shapes before the SWNT growth. SWNTs were then grown with the alcohol gas source method in the UHV chamber. Ethanol gas was supplied to the substrate surface for 1 hour through a stainless steel nozzle. The resulting SWNTs were characterized by SEM and Raman spectroscopy. The wavelength and spot size of the excitation laser for Raman measurements were $785 \mathrm{~nm}$ and about $20 \mu \mathrm{m}$.

\section{Results and Discussion}

Figure 2 shows the Raman spectra for the SWNTs grown under various ethanol pressures for each growth temperature. The spectra were measured with an excitation wavelength of $785 \mathrm{~nm}$ and calibrated relative to the phonon peaks of Si at $520 \mathrm{~cm}^{-1}$ in each figure. For each temperature, high energy regions and RBM regions are separately shown. At $700^{\circ} \mathrm{C}, \mathrm{G}$ band peaks were observed at around $1590 \mathrm{~cm}^{-1}$, which were accompanied with $\mathrm{D}$ band at around $1300 \mathrm{~cm}^{-1}$. In the RBM region, several peaks were observed, indicating that most of the grown CNTs were SWNTs. As shown in Figure 2(b), the $G$ band intensity reached its maximum under an ethanol pressure of $1 \times 10^{-3} \mathrm{~Pa}$, which indicates that the optimal pressure was considerably lower than that in the SWNT growth with Co catalyst, as reported in our previous papers [9].

At $450^{\circ} \mathrm{C}$, the relative intensity of the $\mathrm{D}$ band became strong, irrespective of the ethanol pressure (Figure 2(d)). This indicates that the crystal quality of CNTs was deteriorated by the reduction of growth temperature. In spite of the deterioration, two peaks were still observed at around 352 and $373 \mathrm{~cm}^{-1}$ in the RBM region (Figure $2(\mathrm{c})$ ), in addition to the Si phonon peak at around $302 \mathrm{~cm}^{-1}$. When the growth temperature decreased to $400^{\circ} \mathrm{C}$, the $\mathrm{G}$ band intensity became fairly small and the intensity of the $\mathrm{D}$ band became larger than that of the G band, as shown in Figure 2(f). In the RBM region, only two weak peaks still appeared at around 352 and $373 \mathrm{~cm}^{-1}$ under an ethanol pressure of 1 $\times 10^{-3} \mathrm{~Pa}$, although their intensities were fairly weak. These results indicate that the SWNTs grew from Pt catalysts even below $450^{\circ} \mathrm{C}$, although the yield was reduced.

Figure 3 shows SEM images of the samples grown at 700 and $450^{\circ} \mathrm{C}$ under the optimal growth pressure $\left(700^{\circ} \mathrm{C}, 1 \times\right.$ $\left.10^{-3} \mathrm{~Pa} ; 450^{\circ} \mathrm{C}, 1 \times 10^{-4} \mathrm{~Pa}\right)$. When the growth temperature was $700^{\circ} \mathrm{C}$, web-like SWNTs were formed all over the substrate surface. The length of most of grown SWNTs was several hundred nanometers. On the other hand, at $450^{\circ} \mathrm{C}$, the density of SWNTs was drastically reduced.

Figure 4 shows the relative intensity of the $G$ band in the Raman spectra against the growth temperature for the SWNTs grown under the optimal ethanol pressures. The $\mathrm{G}$ band intensities were normalized by the phonon peaks of $\mathrm{Si}$ at $520 \mathrm{~cm}^{-1}$. As the temperature decreased, the G band intensity decreased monotonically. When the growth temperature was $700^{\circ} \mathrm{C}$, the $\mathrm{G} / \mathrm{Si}$ ratio was 1.8 , but it decreased to 0.12 at $400^{\circ} \mathrm{C}$. In the growth with Co catalyst, the optimal pressure at $400^{\circ} \mathrm{C}$ was $1 \times 10^{-4} \mathrm{~Pa}$, and the $\mathrm{G} / \mathrm{Si}$ ratio and the G/D ratio of the SWNTs grown at $400^{\circ} \mathrm{C}$ were 0.13 and 12 , respectively. The results suggest that for the SWNT growth at low temperature, Co catalyst seems to be more suitable.

To compare the diameter distribution of the SWNTs grown with Pt and Co catalysts, Raman measurements were carried out by an excitation wavelength of $785 \mathrm{~nm}$, and the diameter distributions for the SWNTs grown with Pt catalyst at 400 and $700^{\circ} \mathrm{C}$, and that with Co catalyst at $400^{\circ} \mathrm{C}$ were shown in Figure 5. The diameters were estimated from the Raman shifts of the RBM peaks in the Raman spectra using the relation $d(\mathrm{~nm})=248 / \omega\left(\mathrm{cm}^{-1}\right)$, where $d$ is the diameter of the SWNTs and $\omega$ is the Raman shift in the RBM peak [14]. The percentage of SWNTs of a particular diameter was estimated from the RBM peak intensity, considering that the sum of all peak intensities should be one in each Raman spectrum. The average diameter of SWNTs grown by $\mathrm{Pt}$ catalysts was about $1.0 \mathrm{~nm}$, when the growth temperature was $700^{\circ} \mathrm{C}$, while it decreased to about $0.7 \mathrm{~nm}$ at $400^{\circ} \mathrm{C}$. We also carried out Raman measurements for the samples grown with Pt at $400^{\circ} \mathrm{C}$ using other excitation wavelengths (532 and $633 \mathrm{~nm}$ ), but no distinct RBM peaks were observed. Taking 


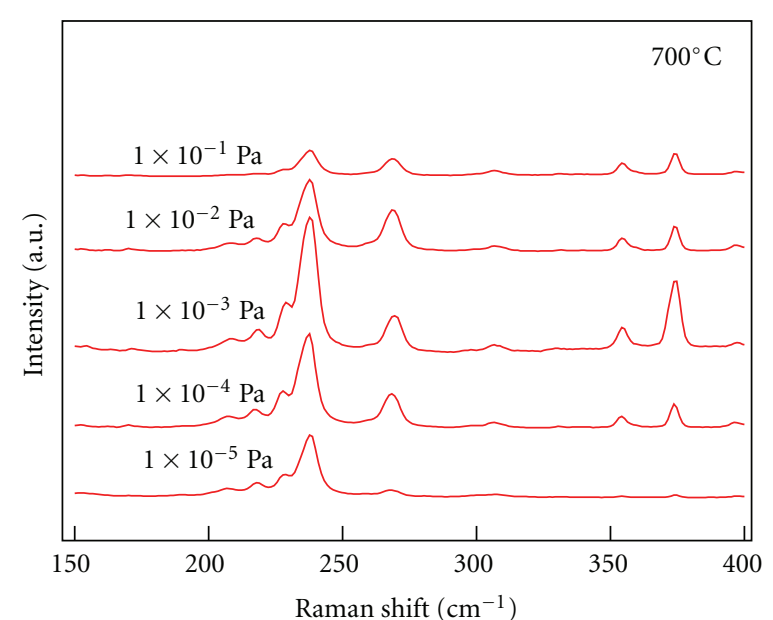

(a)

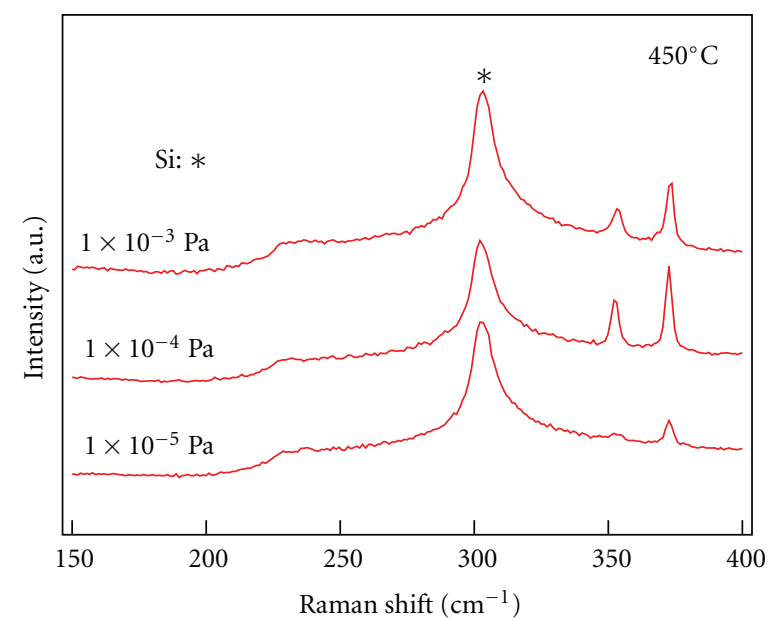

(c)

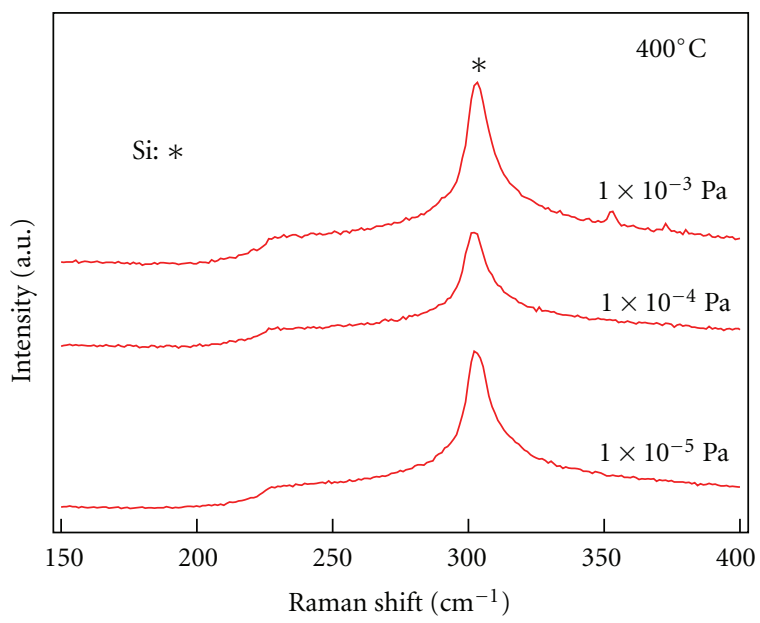

(e)

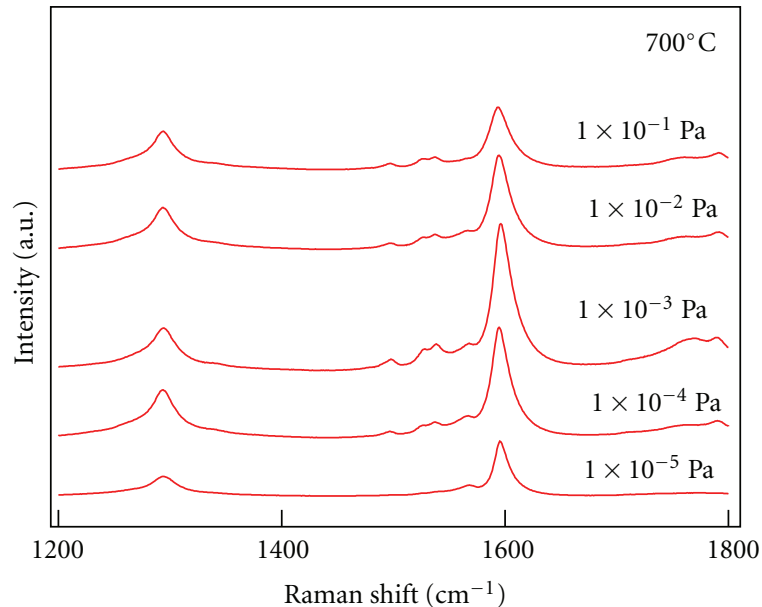

(b)

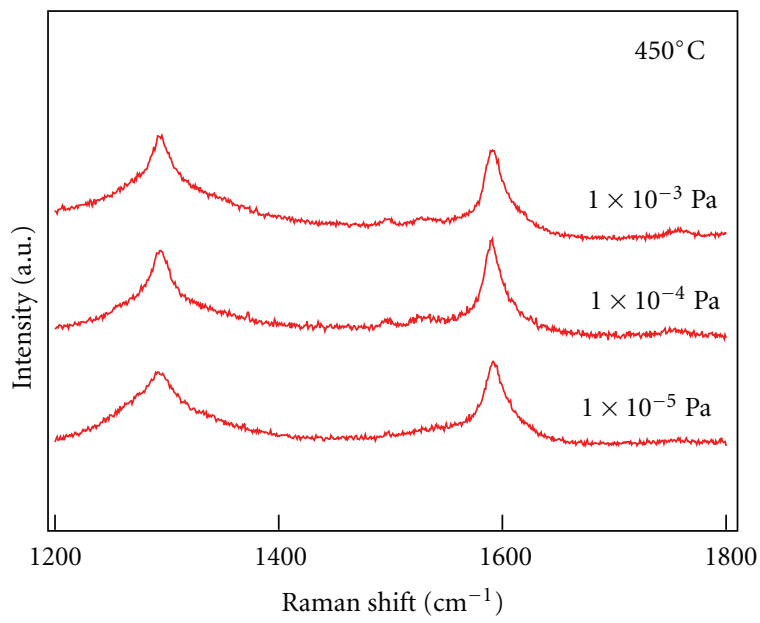

(d)

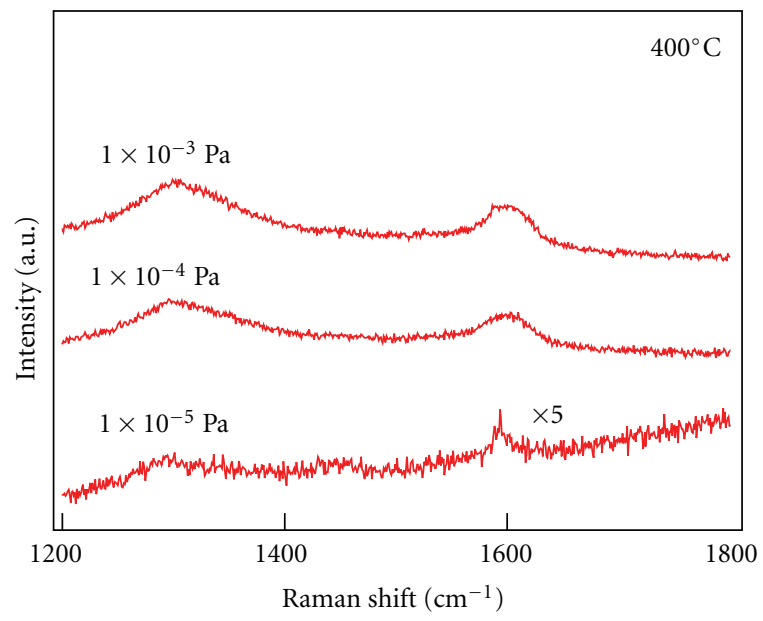

(f)

Figure 2: Raman spectra of SWNTs grown with Pt catalysts under various ethanol pressures at (a, b) $700^{\circ} \mathrm{C},(\mathrm{c}, \mathrm{d}) 450^{\circ} \mathrm{C}$, and $(\mathrm{e}, \mathrm{f}) 400^{\circ} \mathrm{C}$. (a, c, e) RBM and (b, d, f) high frequency regions in the Raman spectra are shown. The excitation wavelength was $785 \mathrm{~nm}$. 


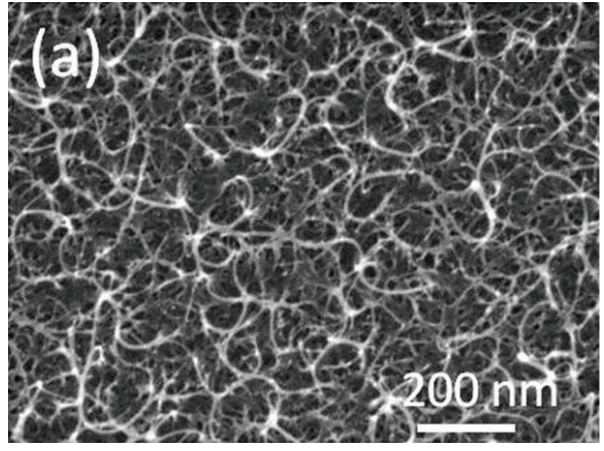

(a)

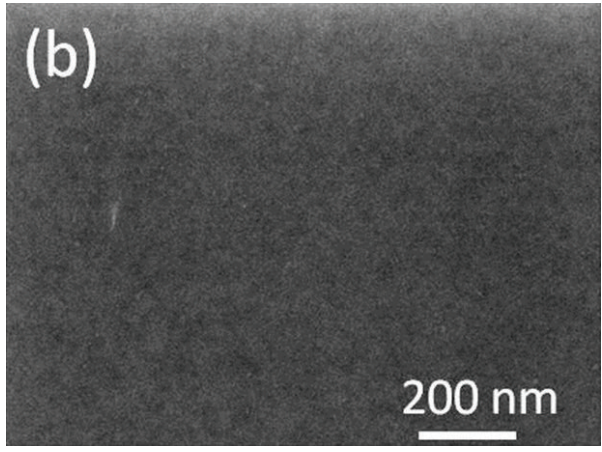

(b)

Figure 3: SEM images of SWCNTs grown with Pt catalyst under the optimal ethanol pressure for each growth temperature. $(\mathrm{a}) 700^{\circ} \mathrm{C}, 1 \times$ $10^{-3} \mathrm{~Pa}$, and (b) $450^{\circ} \mathrm{C}, 1 \times 10^{-4} \mathrm{~Pa}$.

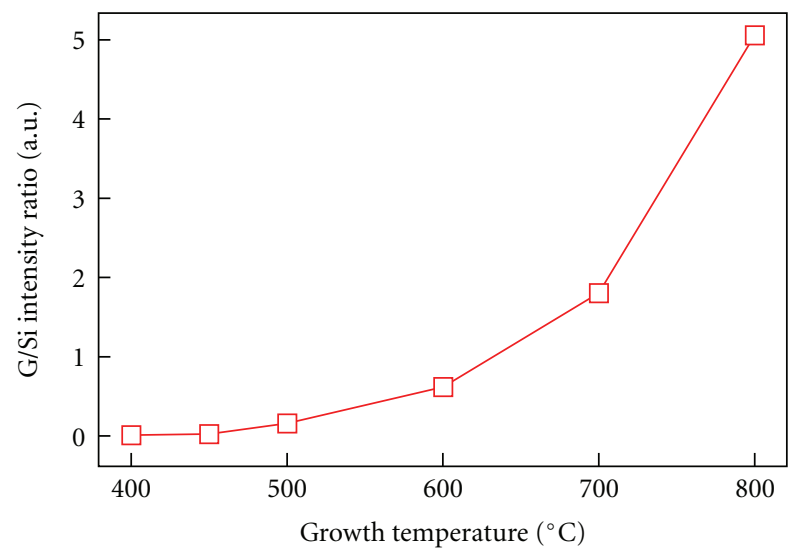

Figure 4: The G band intensity relative to the Si peak $\left(520 \mathrm{~cm}^{-1}\right)$ in the Raman spectra for the SWNTs grown from Pt catalyst against the growth temperature.

into account a so-called Kataura plot, this indicates that the amount of SWNTs of diameters between 0.7 and $1.0 \mathrm{~nm}$ was negligible, which confirms the reduction of SWNT diameters by the decrease of the growth temperature. Our TEM observation showed that average diameter of Pt catalyst particles increased after the SWNT growth, compared to that before the growth. This indicates that the catalyst size increased with the growth temperature. Therefore, we consider that the main reason for the diameter reduction should be due to the decrease of catalyst particle sizes. It should be noted that the average diameter at $400^{\circ} \mathrm{C}$ was much smaller than that for SWNTs grown with Co catalyst at $400^{\circ} \mathrm{C}$. In addition, the diameter distribution of SWNTs grown with $\mathrm{Pt}$ catalyst at $400^{\circ} \mathrm{C}$ was fairly narrow. These results indicate that $\mathrm{Pt}$ catalyst is suitable for SWNTs with the small diameter and the narrow diameter distribution. Considering the relationship between the SWNT diameter and the optical band gap shown in the Kataura plot, the chiral indexes of SWNTs grown from Pt were tentatively assigned to $(6,4),(7,2)$, and $(7,3)$, and those from Co were mainly to $(9,4),(10,2)$, and $(11,0)$.

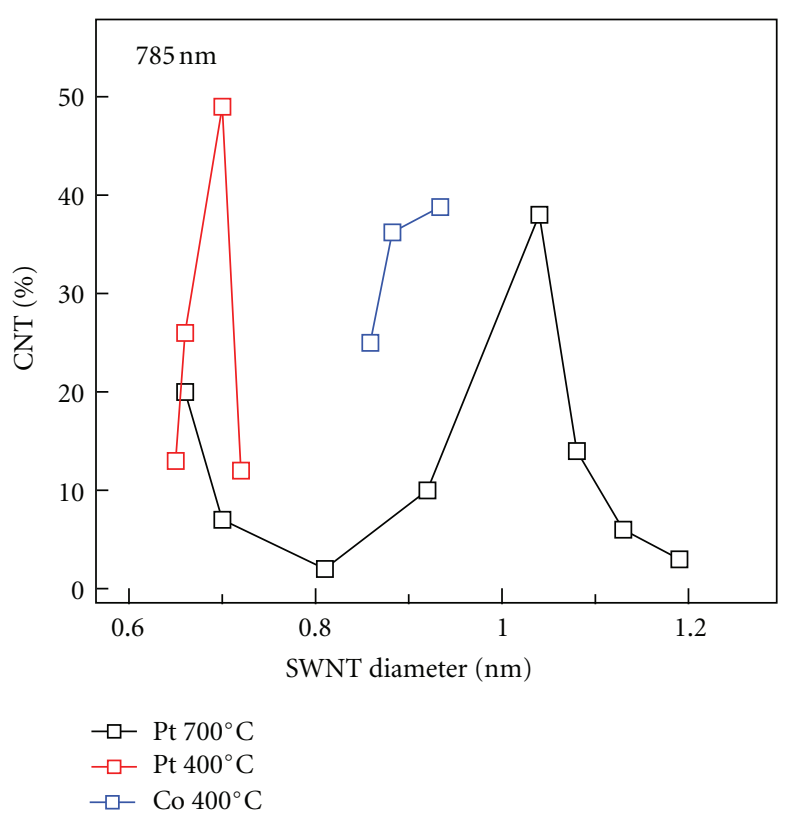

FIgURE 5: The distributions of SWNT diameters grown with Pt at 400 and $700^{\circ} \mathrm{C}$ under an ethanol pressure of $1 \times 10^{-3} \mathrm{~Pa}$ and that with $\mathrm{Co}$ at $400^{\circ} \mathrm{C}$. The distributions were determined from Raman shifts of the RBM peaks in the Raman spectra measured with an excitation wavelength of $785 \mathrm{~nm}$.

It has been reported that ethanol molecules adsorbed on metal surfaces were decomposed through several kinds of reaction pathways at high temperature $\left(>200^{\circ} \mathrm{C}\right)$ and that only a few portions of them were retained as surface carbon $[15,16]$. At the growth temperature of SWNTs, those residual carbon atoms should be crystallized to hexagonal carbon network, forming carbon nanocaps on the catalyst particle surface. Previously, we discussed that the remarkable reduction of optimal ethanol pressure for Pt catalyst was due to the SWNT growth by a diffusion process of carbon atoms on the catalyst surface without dissolution into $\mathrm{Pt}$ [12]. We consider that the small bulk solubility of carbon atoms into Pt leads to the lower ethanol pressure necessary for the 
SWNT growth. In contrast, some portions of carbon atoms on the Co catalyst particles should diffuse into the internal parts of particles, which should increase the optimal ethanol pressures. At low temperature (below $450^{\circ} \mathrm{C}$ ), the SWNT yield from Pt catalyst was drastically reduced, which might be due to the reduction of dissociation of ethanol molecules on the Pt surface. Although the yield of SWNTs grown from Pt at low temperature is not sufficient at present, their diameters were fairly small and the diameter distribution was narrower, compared to those from Co catalyst. These characteristics would lead to advantages in application for fabrication of SWNT devices.

\section{Summary}

We carried out SWNT growth with Pt catalyst at various temperatures between 400 and $700^{\circ} \mathrm{C}$, and the grown SWNTs were characterized by SEM and Raman spectroscopy. Irrespective of the growth temperatures, the optimal growth pressures to obtain the highest yield were considerably smaller than those grown with Co catalysts. In addition, SWNT growth was accomplished by using Pt catalyst even at $400^{\circ} \mathrm{C}$.

\section{Acknowledgments}

This work was supported in part by the Japan Society for the Promotion of Science, a Grant-in-Aid for Scientific Research (C) 21510119. A part of this work was performed in collaboration with the Institute for Molecular Science (IMS), Okazaki, Japan, and Raman measurements were performed using the facility in the Instrument Center in the IMS. The authors are grateful to Meijo University and the Research Foundation for Electrotechnology of Chubu for their financial support.

\section{References}

[1] S. J. Tans, A. R. M. Vershueren, and C. Dekker, "Roomtemperature transistor based on a single carbon nanotube," Nature, vol. 393, pp. 49-52, 1998.

[2] S. J. Wind, J. Appenzeller, R. Martel, V. Derycke, and P. H. Avouris, "Vertical scaling of carbon nanotube field-effect transistors using top gate electrodes," Applied Physics Letters, vol. 80 , p. 3817, 2002.

[3] F. Kreupl, A. P. Graham, G. S. Duesberg et al., "Carbon nanotubes in interconnect applications," Microelectronic Engineering, vol. 64, pp. 399-408, 2002.

[4] M. Nihei, M. Horibe, A. Kawabata, and Y. Awano, "Simultaneous formation of multiwall carbon nanotubes and their end-bonded ohmic contacts to Ti electrodes for future ULSI interconnects," Japanese Journal of Applied Physics, vol. 43, pp. 1856-1859, 2004.

[5] E. Joselevich, H. Dai, J. Liu, K. Hata, and A. H. Windle, "Carbon nanotube synthesis and organization," in Carbon Nanotubes, A. Jorio, G. Dresselhaus, and M. S. Dresselhaus, Eds., p. 101, Springer, New York, NY, USA, 2008.

[6] Y. Homma, D. Takagi, and Y. Kobayashi, "Suspended architecture formation process of single-walled carbon nanotubes,"
Applied Physics Letters, vol. 88, Article ID 023115, 3 pages, 2006.

[7] Y. Homma, F. Maeda, S. Suzuki, Y. Kobayashi, and D. Takagi, "Reaction products of co catalysts in ethanol-chemical-vapordeposition ambient at low-pressure studied by in situ $\mathrm{x}$ ray photoelectron spectroscopy," Japanese Journal of Applied Physics, vol. 46, pp. L148-L150, 2007.

[8] T. Shiokawa, B. -P. Zhang, M. Suzuki, and K. Ishibashi, "Low pressure chemical vapor deposition of single-wall carbon nanotubes," Japanese Journal of Applied Physics, vol. 45, pp. L605-L607, 2006.

[9] K. Tanioku, T. Maruyama, and S. Naritsuka, "Low temperature growth of carbon nanotubes on Si substrates in high vacuum," Diamond and Related Materials, vol. 17, no. 4-5, pp. 589-593, 2008.

[10] T. Maruyama, K. Sato, Y. Mizutani, K. Tanioku, T. Shiraiwa, and S. Naritsuka, "Low-temperature synthesis of single-walled carbon nanotubes by alcohol gas source growth in high vacuum," Journal of Nanoscience and Nanotechnology, vol. 10, no. 6, pp. 4095-4101, 2010.

[11] Y. Mizutani, K. Sato, T. Maruyama, and S. Naritsuka, "SWNT growth on $\mathrm{Al}_{2} \mathrm{O}_{x} / \mathrm{Co} / \mathrm{Al}_{2} \mathrm{O}_{x}$ multilayer catalyst using alcohol gas source method in high vacuum," Journal of Crystal Growth, vol. 318, no. 1, pp. 1101-1104, 2011.

[12] T. Maruyama, Y. Mizutani, S. Naritsuka, and S. Iijima, "Singlewalled carbon nanotube growth in high vacuum using $\mathrm{Pt}$ catalyst in alcohol gas source method," Materials Express, vol. 1, pp. 267-272, 2011.

[13] Y. Mizutani, N. Fukuoka, S. Naritsuka, T. Maruyama, and S. Iijima, "Single-walled carbon nanotube synthesis on $\mathrm{SiO}_{2} / \mathrm{Si}$ substrates at very low pressures by the alcohol gas source method using a Pt catalyst," Diamond and Related Materials, vol. 26, pp. 78-82, 2012.

[14] A. Jorio, R. Saito, J. H. Hahner et al., "Structural $(n, m)$ determination of isolated single-wall carbon nanotubes by resonant raman scattering," Physical Review Letters, vol. 86, pp. 1118-1121, 2001.

[15] A. F. Lee, D. E. Gawthrope, N. J. Hart, and K. Wilson, "A Fast XPS study of the surface chemistry of ethanol over Pt1 11 ," Surface Science, vol. 548, pp. 200-208, 2004.

[16] M. Mavrikakis and M. A. Barteau, "Oxygenate reaction pathways on transition metal surfaces," Journal of Molecular Catalysis A, vol. 131, pp. 135-147, 1998. 

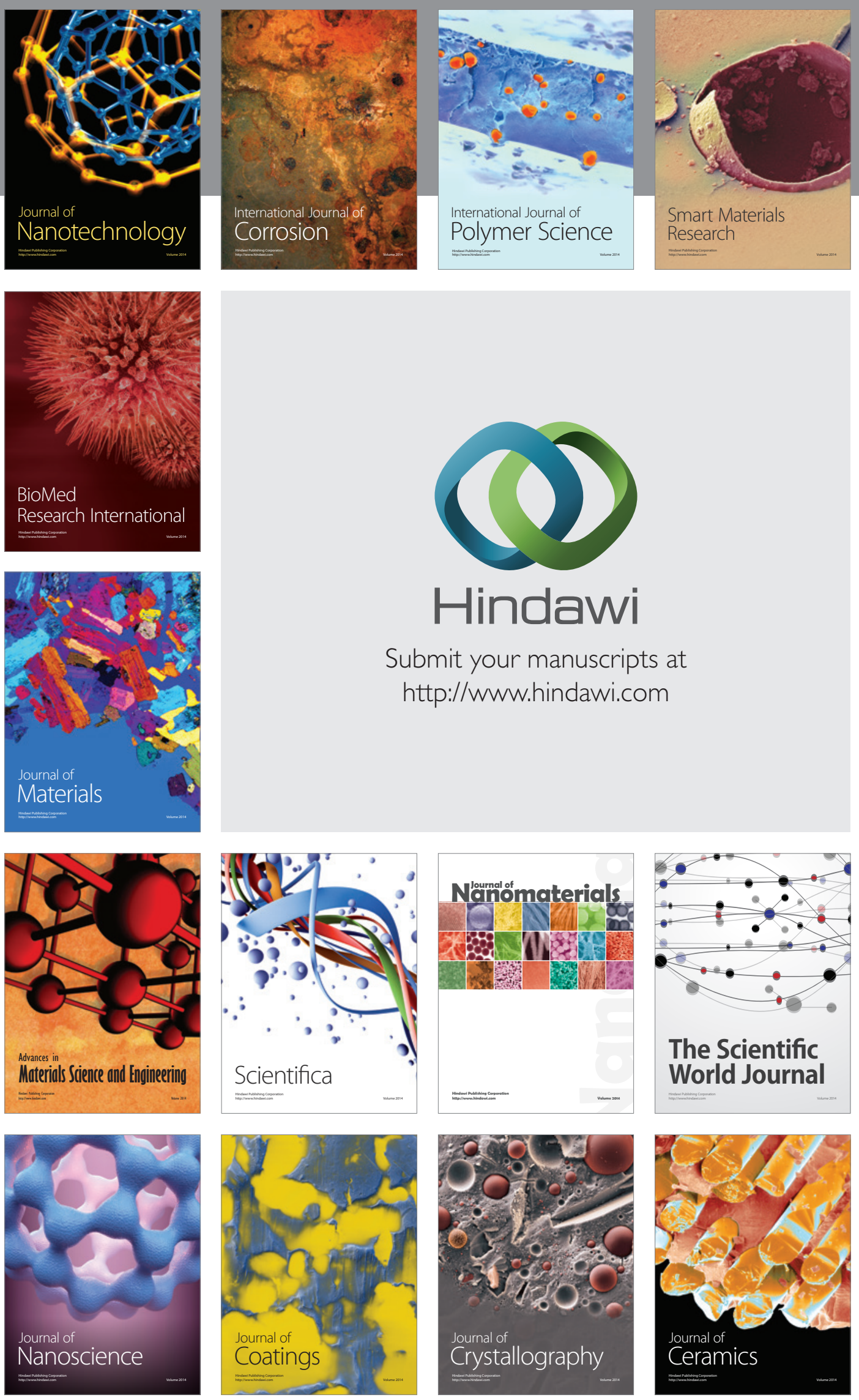

The Scientific World Journal

Submit your manuscripts at

http://www.hindawi.com

\section{World Journal}

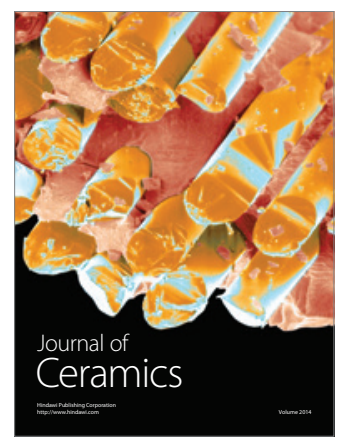

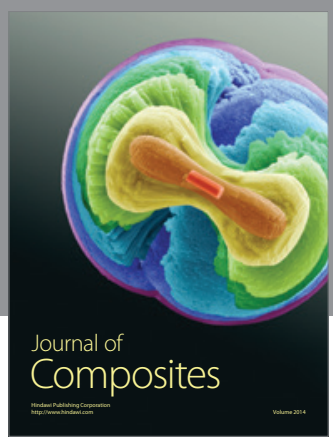
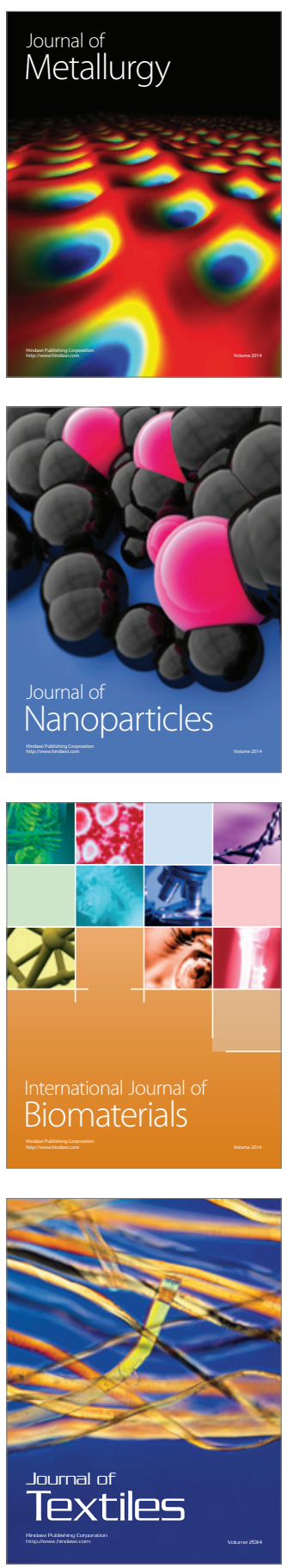